\section{LEVELS OF CONFIDENTIALITY} IN THE PSYCHOANALYTIC SITUATION reported by

ANDREW S. WATSON, M.D.

David Beres opened the panel, commenting that although the title relates to the issue of confidentiality, it may be expected that our discussion will also consider issucs of privilege and privacy as they relate to psychoanalysis.

He noted that the topics would fall into three general categories. First, the specific problems arising in the psychoanalytic situation: "Does the psychoanalytic situation present unique problems? What are the differences and similarities in the psychoanalytic vis-à-vis the psychotherapeutic situation? Are psychoanalytic records subject to subpoena? What problems arise when the psychoanalyst, who may be protected legally in some states, sends a report to a referring physician who does not have the right of privilege, as in a case in Connecticut? What about letters to draft boards, insurance companies, or other third party interests? What will happen if psychoanalysis is included in a possible national insurance bill? To what extent is confidentiality threatened in case discussions, published papers, and in tape recordings used for teaching or research? What are the problems in research situations involving a group of investigators? What are the special problems in analysis of children and adolescents?

"A most knotty problem arises in regard to the candidates in psychoanalysis. Do they as well as other patients retain privilege in communications to educational committees, the membership committee of the American, or other institute administrative bodies? What about confidentiality in the evaluation of persons considered for selection as training analysts?

"A second issue that we will be able to consider is what is now known as the Lifschutz Case." Beres noted that the presence of Dr. Lifschutz would turn the panel into something of a case seminar, inasmuch as his experiences were to be described.

"Third, there are general questions of the legal aspects vis-à-vis the ethical and professional aspects." Speakers would clarify the distinction be-

Held at the Spring Meeting of the American Psychoanalytic Association, Washington, D.C., May, 1971. Chairman: David Bercs, M.D. 
tween confidentiality, privilege, and privacy. Also, the limitations imposed by social and legal policy as they involve criminal cases, psychotic and suicidal patients cannot be ignored. New abortion laws and the designation of "emancipated minors" raise additional problems. "At what age does a minor with venereal disease, drug addiction, or pregnancy lose the right of privilege?"

Eli Marcovitz opened his comments with the statement that, "In psycho. analysis, as in any field of medicine, we begin with the assumption of the analysand's inherent right to privacy, and of the analyst's obligation of confidentiality. The disclosure of one's self to one's self can be difficult enough. There is usually some increment of displeasure from the necessary psychic exposure to the analyst. There should be no danger of further distress from the possibility of the analyst's exposure of the patient to anyone else." $\mathrm{He}$ went on to note the not infrequent occurrence of casual allusion and gossip on the part of analysts about their patients, asserting vigorously that psychoanalysts have the duty to deny themselves the privilege of enhancing their status by associating themselves publicly with their patients.

The need to carry concern for privacy into teaching conferences was also emphasized by Marcovitz. He noted that occasionally interesting patients may not be presented, just because it would be impossible to maintain confidentiality. Marcovitz then turned to some of the "exceptions." The first was in relation to children and adolescents. He noted that "the necessity to preserve life or avert seriously destructive behavior may have to take precedence over the principle of confidentiality. There are times when the decision is not easy, and when the analyst has to calculate the risks." He also mentioned occasions when the analyst may threaten to terminate analysis in order to report dangerous behavior potential, or, alternatively, demand that the analysand withdraw from the risk-taking activity.

The next serious problem involving confidentiality related to the necessity for writing reports about patients. "I doubt that one usually has to report more than the fact that the patient has been seen and the reasons for the form of therapy that has been recommended or instituted." He applicd this principle to reports to insurance companies or draft boards. "If the analyst knows ahead of time that such reports will be requested, he should let the patient know what information may be involved so that the patient may be able to choose whether or not to take the steps which would lead to the request for information. . . . If he is told clearly what he may be letting himself in for, the chances are that he will drop the request." The transference dilemma which this raises was also noted, regardless of whether or not the report turned out to be "favorable" or "hurtful." "Since the presumption is that the analyst's report is in the offing, it is difficult to separate fact from fantasy, and, therefore, difficult to analyze if this is used in the service of resistance." Marcovitz also emphasized the necessity for dealing with the superego aspects of reports, since it is important that the therapists clearly 
do not support any distortion of the truth. "All these factors indicate the reasons that analysts try to avoid such a situation and when it threatens, try to analyze it away."

Next Marcovitz considered the issue of confidentiality in the training analysis. "It has to be known by the institute that the candidate is in analysis and with whom. In this situation we presume that this public knowledge is not a source of any possible injury to the candidate." He then went on to note that among these three, the institute, the analyst and the candidate, there are multiple and complicated relationships, functions, and obligations, chiefly determined by the specter of the fourth member of the group, the future analytic patient of the candidate." Marcovitz emphasized the public responsibility the institute must fulfill when it certifies an analyst, and it was his opinion that analytic candidates should readily accept this responsibility. He then asked, "What is the irreducible minimum of communication by the training analyst which will communicate just this information (". . the candidate's future practice of psychoanalysis is not likely to be hurtful either to the candidate or to his patients') and no more?" In his opinion it should be limited to “. . . a statement from the training analyst that the candidate's analysis has been terminated satisfactorily by mutual consent." If it appears that this statement will not be forthcoming from a given training analyst, Marcovitz is of the opinion that the candidate should be able to turn to another training analyst where he might hope to achieve this result, or to at least ratify the first training analyst's opinion. He believes that the basis for rejection would appear in the candidate's other work and would not need to be designated by the training analyst in his report. If it appeared to the training analyst that "the candidate is unable to accept his own responsibility to his future patients or his current patients, and the similar responsibility of the institute and his analyst, then a successful analysis is impossible in any case. If the analyst's doubts are not resolved in the analysand's favor by the time he wishes to terminate, then it seems to me it is incumbent on the training analyst to let the candidate know that he will not certify to the institute that the analysis is satisfactorily terminated, and that the candidate will be faced with the choice of withdrawing from training or transferring to some other training analyst."

Finally, Marcovitz responded to Beres' question about the selection of training analysts by saying that he was of the opinion that no information or opinion about the proposed training analyst should be revealed by his own former analyst. He noted that this was the practice in his institute and commended it for emulation.

Following Marcovitz's presentation, Beres observed that, in his opinion, a patient's request for any kind of a report always represents a transference problem and reflects a desire on his part to find out what the analyst thinks of him, and may have a "very serious effect upon the transference situation."

Joseph E. Lifschutz was then introduced. The essence of his presentation was a review of his efforts, starting in October 1968, to avoid testifying about 
one of his former patients. Because this case gained such widespread attention, it is appropriate to report it in some detail.

The case arose when a former patient filed suit for damages following a physical assault. In addition to physical injuries, he alleged "emotional damage," and, as is customary in such cases, the plaintift under law automatically "waives his privilege," and prior medical history relevant to the alleged injuries must be made available to the defendant. In this context Lifschutz was subpoenaed by a counsel for defendant. Following his custom of about five years, he refused to make any statement whatsoever about his former patient. The justification for this position was concern for "... what damage would be done to the patient and to the practice of psychotherapy and psychoanalysis by permitting an invasion of therapeutic privacy." Lifschutz made the same response as to insurance companies, probation departments, courts, and other agencies: that anything which he might be able to offer was readily available from any other examining psychiatrist doing a diagnostic examination and not psychotherapy. Defense counsel did not acquiesce in this view and informed Lifschutz that he would be called to court. Lifschutz contacted his own lawyer and appeared with him in county court on 26 Novem. ber 1968 . There the matter was ". . . handled in a routine, peremptory manner. The whole question was given less than ten minutes before the court." The court's decision was to require Lifschutz to respond to the subpoena and submit his records on the former patient.

This judgment was appealed to the Federal District Court, which refused to act favorably. Next followed an appeal seeking a Writ of Prohibition which would have prohibited the lower court judge from imposing the contempt sentence on Lifschutz. The thrust of the Lifschutz argument on this matter was as follows: "The practice of psychoanalysis and psychotherapy call for the free expression of all thoughts a patient may have. Before any person can attempt to express himself freely he must trust his listencr, and he expects that what he says will be held in complete confidence." It was argued that full confidentiality was necessary in order that ". . . the analytic or therapeutic process might unfold itself." His argument was substantially based on the U.S. Supreme Court decision in Griswold $v$. Connecticut (381 U.S. 479 [1965]). The Lifschutz interpretation of that opinion was that it "... upheld among other things the Constitutional dimension for the right to personal privacy, and had asserted a physician's right to practice his professional work in the best manner, a right for the first time separate from the patient's obvious right to the best medical care. My central legal argument rested on Griswold, on my assertion of the right to practice psychotherapy in the standard manner, which to my mind required full confidentiality. A bit more precisely, it required that the therapist be permitted to assert the privilege of silence, independent of the patient's right." Lifschutz cited in support of his views the amicus curiae briefs filed by the American Psychoanalytic Association, the American Psychiatric Association, the California State Psychological Association, and the National Association for Mental Health. 
Lifschutz also argued that he was being denied equal protection under the law "since I, the psychiatrist, did not have rights equal to a clergyman's, under the equivalent conditions." He argued that the psychiatrist as the modern-day confessor should have the same privilege as that afforded to clergymen under California law.

Lifschutz further argued that the psychotherapist needed to have the privilege in his own right because if patients held the privilege, and thereby the option of waiving it, they could not do so with "informed consent." "In psychotherapy the patient has very little knowledge of what his therapist could say, if forced to do so under oath by a patient's waiver. This is an uninformed consent and contrary to a sense of simple justice. To protect the patient, the therapist must be able to assert a privilege for himself if he so chooses."

Finally, he argued that courts could always use alternative means for obtaining such needed psychological information without jcopardizing the therapeutic relationship. He thus distinguishcd the psychotherapeutic situa. tion from the situation of a diagnostic examination.

"By late spring of 1969, the State Court of Appeal and the California Supreme Court had refused to hear (the) case on the Writ of Prohibition ... One final appeal remained, to the United States Supreme Court. Briefs were filed in time before the summer recess of the Supreme Court ..." The Court did not accept the appeal for hearing.

Arguments were finally made to the trial court on 5 December 1969, 14 months after the original subpoena was served. "No attempt was made by the defense counsel or the presiding judge to seriously consider any of the arguments, eloquently presented by Mr. Melchior (counsel for Lifschutz). Much was made of the refusal of the Appeals Courts to grant a Writ of Prohibition, a legally invalid argument because the higher courts' refusal to agree to hear the case was based not on the substantive issues but rather on procedural ones. After a full morning of interrupted arguments I was sworn in and then asked by the judge whether $I$ had ever seen the teacher and whether I had any records. On all the grounds cited earlier I refused to answer. I was then cited by the judge for being in contempt of court and at 12:45 p.m. was remanded to the custody of the bailiff and sent to jail until I agreed to answer. The judge denied my attorney's motion that $I$ remain out of jail pending appeal."

Lifschutz was to remain in jail for three and a half days before the California Supreme Court issued a Writ of Habeas Corpus which resulted in his. release. They also agreed to hear arguments on the substantive issues. A brief was filed along with the several amicus curiae briefs, and argument was held before the Supreme Court of the State of California on February 4, 1970. On 15 April 1970 a unanimous opinion was handed down, upholding the contempt citation by the lower court.

After acknowledging the presence of the psychiatrist-patient privilege in California law and the importance of psychotherapy in contemporary so. 
ciety, the Court proceeded to reject Lifschutz's major contention that the psychotherapist should himself have privilege. Lifschutz states that "the Court did not accept Griswold as clear precedent, recognizing the physician's own right to practice in the best manner. It also rejected my claim for the exceptional need for confidentiality in the practice of psychotherapy. . . . However, the Court's opinion seems weak to me at this point, since my claim was supported by four amicus curiae briefs representing all major professional organizations and a lay organization as well, and the claim was never denied or opposed by any evidence or testimony against it. The Court merely asserted that it was not true."

Having denied privilege to the psychotherapist, the Court went on to discuss some of the issues related to the concept of waiver and the extent to which the waiver exists. Lifschutz cited the Court's opinion on p. 36, in which they said

In the light of these considerations, the "automatic" waiver of privilege contemplated by section 1016 (which removes the privilege of silence when mental health is put in issue) must be construed not as a complete waiver of the privilege but only as a limited waiver concomitant with the purposes of the exception. Under Section 1016 disclosure can be com. pelled only with respect to those mental conditions the patient-litigant "has disclosed by bringing an action in which they are an issue" . . Communications which are not directly relevant to these specific conditions do not fall within the terms of Section 1016's exception and therefore remain privileged. Disclosure cannot be compelled with respect to other aspects of the patient-litigant's personality even though they may, in some sense, be "relevant" to the substantive issues of litigation.

Further on in the opinion, the Court states

Although we doubt that the ten-year-old therapeutic treatment sought to be discovered from $\mathrm{Dr}$. Lifscliutz should be sufficiently relevant to a typical claim of "mental distress" to bring it within the exception of section 1016, we cannot determine from the pre-state of the record whether plaintiff's "mental and emotional" distress is merely the "normal" distress experienced as a result of physical assault or whether it includes unusual or particularly serious elements from which prior history may be directly relevant.

From this part of the Court's opinion Lifschutz observes that “. . . here is a new concept. A patient may now put his mental health in issue under certain circumstances without the danger of disclosure, by claiming that the mental distress was the 'normal' distress accompanying the physical injury, and not more. In so doing he would protect not only his past psychiatric history but even ongoing psychotherapy at the very time of the injury. No such protection has existed before for psychiatric patients." 
After the Supreme Court's opinion was handed down, the original litigation procecded. At a deposition hearing on May I, 1970, Lifschutz acknowledged that he had seen the patient in 1955, but would add no further information, stating that he believed the information to be nonrelevant. The trial court reconvened, and defense counsel again sought to obtain Lifschutz's records. After several delays, the trial judge took the patient's record to study it and to detcrmine whether it contained any relevant material. On June 4 th, he ruled that it did not. "I had purged myself of the contempt citation by my limited testimony." Summarizing the situation, Lifschutz stated that the situation now is that "... the patient retains all rights and control over the psychotherapist's revelations. Attorneys need to instruct litigantpatients of their rights and powers over such private material."

In the last portion of his presentation, Lifschutz suggested that given the continuing uncertainty about confidentiality it might be wise for psychotherapists to keep limited records about their therapeutic transactions. It was his opinion that this would permit casier regulation of the matter of confidentiality by psychotherapists. Finally, he expressed his gratitude for the extensive support by colleagues and psychiatric organizations during the extended period of his involvement in this litigation.

Beres thanked Lifschutz on behalf of the audience for his gencrosity in sharing his experiences. Beres posed the question of what would happen if an analyst declined to report to an insurance company about his patient who was receiving some of the cost of analysis from the insurance carrier and then the insurance company referred the patient to a nonanalyst for evaluation about the analytic progress. Because the nonanalyst would be relatively uninformed and possibly hostile, might this not raise some problems for the analysand with his insurance company? Next, Beres raised the issue of "informed consent," anticipating this would be discussed later. He also noted the importance of the question of whether analysts should claim the same privilege as that held by clergymen and lawyers. Finally, Beres asked the tantalizing question of whether there was a breach of confidence when the therapist presented information to the judge to help him evaluate whether to exclude it on the basis of privilege or nonrelevancy. This last question, needless to say, has important operational consequences.

Jay Katz opened his remarks saying, "Though I will confine my analysis to the Lifschutz Case, the problem has much wider implications, and includes such issucs as the respective rights of professionals, patients, and the state to maintain confidentiality or to require disclosure." Katz then raised the question, "Why confidentiality? What functions does it serve for the psychoanalytic process and the participants? Particularly in the context of the Lifschutz Case, I would suggest that for the analyst his promise of confidentiality safeguards the analytic process; for without this he could not insist that analysands follow the most fundamental prerequisite of analytic techniquefree association. Leaving ethics aside, which demands separate analysis, con- 
fidentiality is an essential component of our technique whose guardian . . . must be the analyst. For the analysand, confidentiality promises that his associations will remain in the confines of the consulting room unless he chooses to communicate them to others. This freedom to communicate, however, is not an unlimited one, for we all know that the analyst, in order to safeguard the analytic process, may have to place restrictions on such disclosures whenever they threaten to dilute analytic work. The function of confidentiality to protect privacy in the analytic situation is not safeguarded as closely as it should be. It has been claimed that the analyst's exercise of privilege is (1) an absolute professional right of the analyst and (2) protects the analysand's propensities for acting out unconscious and ill-considered impulses, or protects the analysand's uninformed decisions about release of analytic data." Katz expressed great doubt about the validity of the notion of the analyst protecting the patient against himself. "There may be at least one other function of confidentiality ... namely, to protect the analysand from undue pressure by others for release of analytic material."

"My formulation, that confidentiality should first of all be viewed as a safeguard of the analytic process was stimulated by Dr. Lifschutz's position; for his assertion of absolute and uncompromising confidentiality left me with the nagging question: May not absolute confidentiality at times undermine, rather than protect, the analytic process?

"Though I disagree in part with Dr. Lifschutz's position, I admire his course of action. He had strong convictions about the practice of our profession, convictions which conflicted with existing laws and placed him in danger of imprisonment-and indeed he spent three and a half days in jail. Unlike most of us, who under similar circumstances, would compromise what otherwise we consider our professional obligations, he did not retreat. In taking affirmative action he joins that small band of physicians who have done great service to medicine by seeking legal redress." Kat $z$ then cited the cases of Drs. Bourne and Buxton in their crusades for more appropriate abortion laws and laws regarding contraceptive information. "Indeed it was Dr. Buxton's case which led to the important opinion of Griswold v. Connecticut, so centrally relied upon by Lifschutz." He went on to say, "I believe that Dr. Lifschutz's stand will eventually change, even more than it has already, the legal position with respect to confidentiality, though along somewhat different lines, I hope, then he has envisioned. (I should note that the factual situation of In Re Joseph E. Lifschutz was a bad one on which to base the legal battle for which Dr. Lifschutz must have prepared himself for some time. That the results turned out as well as they did demonstrates that there are exceptions to Justice Holmes' famous dictum 'that hard cases make bad laws.')"

Katz went on to summarize the issues that Lifschutz had argued in his case: ". . . that the Court-imposed order to reveal information about his patient interfered (1) with his personal constitutional right to privacy; (2) his right to effectively practice his profession; (3) the constitutional privacy 
right of his patients; and (4) his equal protection rights under the 14th amendment, because, for example, the clergy in California and elsewhere have been granted absolute privilege.

"I will very briefly dispose of what I consider minor issues. The juxtaposition of clergy and psychoanalyst is probably a good legal ploy that should have been made in support of Dr. Lifschutz's objective; but inviting comparisons between the rights and duties of different professions raises more problems than it settles. The heavenly contracts between priest and penitent are not comparable to the earthly ones between analyst and analysand, or lawyer and client."

Summarizing his views about privacy, Katz stated, "As far as an all-pervasive personal or professional constitutional right to privacy is concerned, it does not exist and I will leave it to constitutional lawyers to argue whether it should or not."

Katz then turned to the question of whether or not a psychotherapist is handicapped in his professional practice if he cannot invoke absolute privilege. "It seems to me that breaks in confidentiality raise different issues if disclosures are initiated by the analyst or at the request of the analysand. This touches on Dr. Marcovitz's paper ... here I have always defended the controversial position that we cannot compromise our promise of confidentiality. We must leave it to others to safeguard life or avert seriously destructive behavior. It is our professional and social responsibility to keep our doors open to those who are also struggling with their destructive impulses, and work with them as best we can and as long as we are able to do so. If implicitly or explicitly we have promised confidentiality, we must then abide by it, for otherwise we can never be sure again of this promise. . . Thus, I would agree with Dr. Lifschutz that confidentiality should rarely, if ever, be broken by the analyst over the objections of his analysand."

Katz vigorously affirmed Marcovitz's concern about cocktail party gossip regarding patients. He then went on to ask about the "scientific" utilization of patient information. "Should we present any patient data without the permission of the analysand? Is it the duty of our Program Committee and the editors of our scientific journals to ascertain that such permission has been obtained? Or, can we agree with Freud's famous defense in publishing the Dora case, keeping in mind that his prediction about maintaining Dora's anonymity did not turn out to be correct."

Katz stated that he was "puzzled by Dr. Lifschutz's lawyer's statement that 'a doctor has an independent duty to all his patients not to let any patient make him violate his oath that he has given to all patients at once. So it is his privilege.' Does this mean that we swear to our analysands not to disclose anything with or without their permission? I am not aware of this, and I would be reluctant to make such an all-embracing contract. I can envision situations in which the analysand and I could agree to making disclosures to others, and that, indeed, not doing so might undermine the analytic process; for example in refusing to write a letter to a draft board 
that " $\mathrm{X}$ " is in analysis with me. Colleagues whom I greatly respect have told me that, for example, writing such a letter to a draft board or making a statement in a custody dispute always has detrimental effects, indeed will destroy the analytic relationship. I have thought hard about this and find it difficult to embrace such a position. I agree that such decisions should not be made as a matter of course and should be given, like everything else in analysis, careful analytic scrutiny. My disagreement rests on an inability to be guided by any apodictic prescriptions-absolute positions have never represented to me the spirit of psychoanalysis."

Katz set forth some of his underlying assumptions about psychoanalysis which should be kept in mind when considering whether the analyst should intervene or not in the reality situation of his patient: "(1) Most important, the analytic process is best safeguarded by avoiding, whenever possible, utilization of parameters; (2) the problems which may arise from an intervention should be analyzable in a satisfactory analysis, even though they may prolong the analysis; (3) a decision to intervene deserves a greater scrutiny of countertransference than of transference problems; (4) a decision not to intervene can under certain circumstances be more detrimental to the analysis than the decision to intervene because the analysand may justifiably feel victimized by a monolithic principle of technique whose verity is difficult to establish; and (5) the adverse effect on the analytic process of a carefully considered decision to intervene may only bring to the surface transference and other problems that even in the absence of such an intervention would eventually have resulted in an unsatisfactory completion of the analysis. Again, the general proposition I wish to advance is that confidentiality may at times have to be broken at the request of the analysand and therefore is never absolute. Dr. Lifschutz asserted that the privilege of disclosure belongs to him. This could mean that he would never exercise this privilege and that indeed he advocates that a psychoanalyst should never be asked to disclose anything about his analysands to others. It could also mean that, either with or without discussion with his analysand, he should be the one to decide when to invoke the privilege and, if with discussion, when to overrule the analysand's wishes. Each of these positions creates difficult problems which require scrutiny."

Lifschutz based this on the concept that the patient cannot make a meaningful consent. Katz disagreed with this and noted that when he has thought through what he will say in court, he can readily clarify and communicate this information to both the patient and his lawyer so they may jointly decide upon a course of action. He did not, therefore, view this as an important problem. Katz agreed with Samuel Lipton that psychoanalytic patients, in contrast to some other psychiatric patients, should have the capacity to make a properly informed consent.

Katz also concurred with Lifschutz in the notion that psychiatric information should be obtained by another psychiatrist rather than from the treating psychotherapist. He told of a proposal he had made in discussions with the Connecticut legislature, in which there should be no obligatory 
waiver on the part of the plaintiff-patient in civil actions. This judgment was made not in order to protect therapists, but was for the benefit of the patient. The most important lesson to be drawn from Lifschutz is the need for the professional community to foster statutes that will better protect the rights of patients.

Finally, Katz disagreed with Lifschutz about changing the privilege statutes so as to protect the therapist's position rather than the patient's. He would retain this right for the patient. A patient may believe that his present or former analyst is his best witness. This could lead, however, to termination of the analysis if the covert reason for the testimony is to promote a statement from the analyst about what he thinks of the patient, and that fact cannot be thoroughly analyzed. The final decision about the privilege, though, belongs to the patient, and Katz would not delegate this power to the analyst in the guise of protecting the patient. "In my years at the Law School, I have seen the greatest abuses perpetrated by the state and by professionals in the name of the best interests of others." Katz went on to quote Isaiah Berlin who said, "To manipulate men, to propel them toward goals which you-the social reformer-see, but they may not, is to deny them their human essence; to treat them as objects without wills of their own is therefore to degrade them. That is why to use [men] as means for my, not their own independently conceived ends, even if it is for their own benefit is, in effect, to treat them as if they were sub-human. To behave as if their ends are less ultimate and sacred than my own!" Katz was certain that Lifschutz would not desire such an end and this fact was well perceived by Justice Tobriner who, in his opinion, said, "for the psychotherapist to assert absolute privilege concerning all psychotherapeutic communications ... would lock the patient into a vise which could prevent him from waiving the privilege without the psychotherapist's consent."

In closing, Katz noted that "Psychoanalysts have learned much about the misuse of omniscience, especially in situations where one party is given authority to make decisions for others. I do not see [analysts] as their analy. sands' protectors. ... In that context the right to self-determination, however irrational the decisions, belongs to the analysand-for psychoanalysts in the psychoanalytic situation, we are not our brothers' keepers-we are only their interpreters."

Andrew S. Watson began by concurring with Katz's views regarding the Lifschutz case. This he attributed to the fact that both "had been consorting" for some time with lawyers. He stated that he would explore some issues which relate the contract between patient and doctor to maintain privacy, and the physician's self-imposed ethical duty to perform his medical procedures "in the best interest of the patient." The latter ethical proposition "gets elaborated in various ways, and sometimes the elaborations are followed in such a monolithic way that their fundamental purpose is defeated."

Lifschutz, said Watson, had provided our profession with an excellent 
case around which to analyze such questions. He agreed with Katz that while Lifschutz was to be commended for his stellar defense of what he believed to be appropriate, the case was not a good one in which to exercise this concern. Lifschutz, predicating his principal argument on Griswold v. Connecticut, suggested that the Court in that case offered the physician some right to exercise privacy on his own behalf. In Watson's opinion, Griswold permitted the physician in that case to intervene on behalf of his patients, or as lawyers would say, it gave him "standing" to intervene. It left the matter of the patient's privacy where it had been before, though it did make some of the elements of personal privacy guaranteed by the Constitution more explicit.

Much confusion exists in the minds of many professionals about the distinction between privileged communication and confidentiality. Privilege relates strictly to the presentation of confidential information in the context of a trial. Privileged communication is a right which belongs to the patient, when it has been so defined by statute, that prohibits a physician from testifying about confidential information gaincd during a therapeutic procedure unless the patient "waives" the privilege, or unless there is an automatic waiver created by statute and related to such actions as a suit for emotional damage consequent to unlawful injury. Watson emphasized the great importance of each psychotherapist's knowing the precise nature of the laws which operate in his own jurisdiction. Such a patient-right exists now in upward of 30 states. Confidentiality is, in the first instance, a purely ethical obligation which doctors impose upon themselves. It acknowledges the necessity not to reveal confidences because such behavior would be so potentially harmful to patients, or at least would usurp the patient prerogative of privacy. This ethical consideration is reinforced in law by the doctor-patient contract obligation to maintain privacy. To brcach this obligation can result in a "tort" suit for damages. (A tort is an unlawful act which is not a crime.) The confidentiality of the doctor-patient relationship is ordinarily not made explicit nor are the problems discussed which might necessitate some change in the relationship during the course of therapy. Just as a therapist will explicitly work out such matters as fee and schedule with his patient, so he should work out the matters which are the subject of this panel discussion.

Watson referred to another situation which has been publicized widely, that involved art work and information obtained during the analysis of a famous artist. He thought using that material reflected a breach of confidentiality. Some recent accounts of the incident suggest that the artist's wife gave some kind of permission to reveal the material, and it appeared in a brochure describing the drawings. This incident raised the interesting question of whether or not a decedent's surviving spouse may give permission to void the confidential relationship with a therapist. Watson predicted that such would probably not turn out to be the case. The only similar circumstance when this question may arise is in connection with the legal question of "competence to draw a will." In that situation, a therapist's insight about the patient's mental abilities may be necessary to litigate the will. This not 
only relates to the contending rights of survivors, but also may be necessary to assure fulfillment of the wishes of the testator. On some occasions a therapist's refusal to testify on such issues might totally thwart the intentions of the former patient. That would hardly seem justifiable under any circum. stances.

Watson thought most of the discussion in the psychiatric press about the Lifschutz case was quite naive regarding the legal issues involved. This demonstrated graphically the necessity for psychotherapists and other professionals to learn about such legal problems in order to deal with them more accurately.

With regard to the question of who should possess the right to protect the patient's privacy, Watson vigorously supported Katz's view that this should belong to no one but the patient. He too has encountered many situations in which privacy was inappropriately handled, even though by conscientious persons.

Watson reiterated the Katz position that the Lifschutz case was a poor one in which to deal with the question of privileged communication. It was his impression that under no circumstance could the doctor have succeeded in withholding the legally relevant information about his patient. No other psychiatric examiner could provide information or evidence which would measure up to the quality of that which was in possession of a therapist who knew the litigant well before the time of the alleged tort. This would be true whether or not the information was needed by plaintiff to make out his own case or by defendant to challenge it. It is a fundamental principle of the law of evidence that whenever possible, "the best evidence" must be introduced to support a proposition. Since one of the issues in plaintiff's case here related to what his prior mental state had becn, Lifschutz's observations as a treating therapist would be crucial to an appropriate defense exploration, and indeed it should have been related to that of plaintiff as well.

Watson elaborated further upon the nature of the tort action which involves an allegation of emotional damage. Plaintiff's allegation must state that due to or but for the unlawful act by the tort-feasor (the one who did it) the damaging emotional reactions would not have occurred. This means then that plaintiff may claim (1) that prior symptomatology was aggravated or (2) new emotional symptoms were generated by the tort. Defendant, on the other hand, would attempt to claim that (1) no new symptoms were generated or (2) that the symptoms were already present and might have been, at best, only slightly exaggerated. The amount of damages awarded would obviously be substantially lower for aggravation, and absent for a demonstration of no change of status. "Psychotherapists as a group may disagree with the legal concepts stated in this area of law, but that disagreement is irrelevant in any instant case. Our patients have the right to pursue their legal interests according to the law, whether we agree with the law or not." If Watson had been engaged by counsel for the plaintiff in this case, the first thing he would have done would have been to urge counsel to obtain Lifschutz's notes. That 
would represent the most powerful information which could be utilized to either demonstrate or disprove the changed emotional status needed to seek damages for emotional injury. (Sometimes, in fact, such prior therapeutic material results in the expert's urging counsel not to sue because he can not demonstrate the development or exacerbation of emotional injury due to the alleged tort.)

Watson explored the point made by Lifschutz relating to the question of legal relevancy of material from psychotherapy. He disagreed with Lifschutz that new law was made in this case, but agreed that the opinion elaborated the issue of relevancy more clearly. He noted that this case once more demonstrates the principle that mere presence of a statute or a precedent does not guarantec its appropriate utilization. Such use may be assured only through development of appropriate professional skills in both lawyers and psychotherapists. Turning to the inferences drawn by Lifschutz from the presence of the amicus briefs filed by various professional organizations, he noted that in his experience most such briefs tend to be of poor quality, since they quite routinely fail to comprehend fully the legal issues which are in argument. He has vigorously opposed filing such briefs on behalf of organizations like the American Psychiatric Association. It was his impression that we often discredit ourselves with foolish or naïve positions.

The speaker examined several circumstances in which the contract of confidentiality probably will be voided by one or the other party to it. He speculated that probably every psychotherapist would deviate from the absolute contract at some point, and when he did so, would find some way to make the deviation logical. The first set of alterations considered were those effected by the patient. If he sues in tort for emotional damages, in every jurisdiction there will be an automatic waiver of his privilege. Then ordinarily the therapist will be approached informally or through subpoena, and he will be asked to produce his records. It is important for a therapist to understand the nature of a subpoena. This document will be made out by counsel for one of the parties to the action who has, or believes he has, a vested interest in the information or the witness. He then presents the subpoena to the judge, who usually signs it without question. The average layman, upon receipt of such a subpoena, instantly imagines himself under the authoritative scowl of the court. His anxiety will discomfort him sufficiently so that he does not appropriately clarify matters for himself. If a therapist believes that his patient's psychotherapeutic material may be inappropriately revealed, he can often stop the revelation cold in its tracks by showing the lawyer what would be revealed. Since in nearly all cases the psychiatric data will be both pro and con so far as the case is concerned, such a presentation often will give lawyers pause. Similarly, the content of what would be described by the therapist should be thoroughly discussed with the patient, so that he too may make a conscious choice about whether or not he wishes to proceed with his law suit. In the Lifschutz case, the plaintiff, if he indeed had a good case, should have been eager to have Lifschutz describe his prior con- 
dition inasmuch as that would give him "solid genetic information" about his pretort condition. It is indeed a lucky plaintiff who has that kind of information available to him. If the contrary were true, then very probably plaintiff's counsel would have found a way to avoid going to trial, for the therapist's information might lose, or at least minimize his action. Such a result is precisely how legal procedures seek to find "justice."

Watson could see no logical reason for an analyst to avoid communication in the manner described above. He felt that such a situation provided an excellent opportunity for the therapist to explore vigorously some of the transference vs. reality problems relating to the patient. He acknowledged that there are also many countertransference problems involved in this problem, and this case would make an interesting launch point for a vigorous theoretical exploration of the interrelationship between transference and countertransference issues. Since the analytic process is involved with improving the patient's skill for coping with reality, he believes that it is completely untenable for an analyst to obstruct the reality option of a patient to sue for damages allegedly done to him. He would view such a stance, not only as a danger to the therapeutic process between analyst and patient, but also as a pre-emption of the patient's legal rights.

Watson then turned to various situations in which the analyst might wish to "void the contract" of confidentiality. There are a whole series of situations which relate to the issue of the patient's "competence." For example, there is the presumption that he is competent to contract with the therapist to arrange a schedule and a fee. Quite commonly during the course of therapy, the patient's level of competence may be altered so that a ques. tion will arise about his ability to make decisions rationally on his own behalf. From that point in time, anything he does will be from a state of legal jeopardy, since the testing of that state is usually done after the fact. These matters are made more sticky by the fact the therapist himself may be in some legal jeopardy. For example, in most jurisdictions the therapist will have some obligation to prevent suicide. Failure to deal adequately with this matter may make him vulnerable to a malpractice action. Similarly he may have some obligation to prevent homicide and conceivably even some lesser crimes. Should such a suicide or homicide occur, and should the therapist be sued in connection with them, it would be unlikely that most therapists would be loathe to reveal information from treatment which would be useful to their defense.

If one accepts the fact that one has an obligation to prevent suicide or some other violence, then, when prevention procedures are invoked, a similar dilemma occurs, since the therapist will have to reveal confidences to make hospitalization possible. When such actions are taken by analysts, they frequently appear to spread confusion by camouflaging their part in initiating hospitalization. It should be clear that failure to acknowledge our participation in this act would considerably confuse the transference and militate against the patient's dealing with the reality problems around him. 
The final situation mentioned had to do with the questions concerning training analysis. Watson concurred with the prior speakers who noted that the therapeutic contract between candidates and training analysts was very unclear. He speculated that it will probably become a legal necessity to be able to account logically for terminating the training of an analytic candidate. After such a large investment had been made by the candidate, the reasons for termination should not only be clear, but they should be made available to him. The candidate will have the right to know why he's not adequate and who thinks that about him. This would fall under the general rubric of "due process of law."

Watson concluded by addressing himself to several suggested remedies for problems that now exist. The first clear need is that of educating psycho. analysts and psychiatrists about the complex and delicate problems involved in working out their contract with patients as it relates to confidentiality and the potential problem of privileged communications. Nowhere in most current training does the student psychotherapist receive any information on this subject. Such suggested training should improve our skill for dealing with these complex matters which involve law and psychiatry. This knowledge should be built into the training programs of all psychoanalytic institutes. Many of the problems regarding the analyst's relationship to legal processes which are now regarded as transference problems are more probably issues of countertransference. Watson mentioned the enormous narcissistic stress placed upon a person when he testifies, and how that forces him to explain his opinions and how he arrived at them. He contrasted this with the rather different emotional situation when the analyst is working from the head of the couch where he can view most challenges as being related to resistance, defensiveness, or some other dynamic matter. The nature of these problems deserve intensive concern and study on the part of all analysts everywhere.

Before returning to the panel for questions and further clarifications, Beres mentioned the current suit brought by a New York City woman whose psychotherapeutic interview was utilized for teaching purposes without her permission.

Samuel D. Lipton of Chicago asserted his agreement with Katz and Watson regarding the Lifschutz case. He had aiways felt it dangerous to place the question of privilege in the hands of therapists. He noted the sharply distinguishable value systems between the legal and the therapeutic worlds. The ethical problems which the physician faces regarding the confidentiality of his patients communications are so important that mandatory training analysis should perhaps be abandoned in order to assure confidentiality to the person in analytic training. Lipton noted the basic conflict which the therapist encounters when he enters the judicial system, and he suggested that we should train ourselves to think about our patient under those circumstances as "litigant" rather than "patient." It is the only way we can work toward getting our patient his just due in the litigation process. He 
confirmed Watson's view that knowledge of the judicial process makes it relatively easy to relate appropriately to both the legal process and the medical involvement of the patient. He felt that there is no basic difficulty in helping a patient to make an "informed consent." It can be done in psychiatry just as well as in neurosurgery. He also concurred with Katz and Watson regarding the fact that the judicial system has its own safeguards for those who participate in it, and we should willingly involve ourselves, making full use of those safeguards.

Lipton noted that the plaintiff in the Lifschutz case (Lifschutz's former patient) was suing for $\$ 175,000, \$ 50,000$ of which was for emotional damages. All parties had lawyers and all were deserving of their full legal rights in regard to information and appropriate defenses. Defendant was quite within appropriate bounds when he sought to find out the background characteristics of the plaintiff in the case. Lipton noted that ". . . we have to be very cautious about claiming that we know better than the processes of the law that we have entered into . . " how to handle matters. He urged all to read the opinion of the California Supreme Court, which he felt to be a very detailed and excellent document which brought matters up to date but didn't advance them, a view contrary to that held by Lifschutz.

A question addressed to Dr. Marcovitz from the floor asked, "whether an institute, upon rejecting a candidate, should give a full explanation to him about the reasons for the rejection?" Marcovitz began by agreeing with other panelists that we shall probably in the near future be forced to justify our action if we drop a student from an institute. Also, he felt that an applicant should be given some information about why he is not accepted. Marcovitz noted that in his institute, the director will have an interview with the candidate and help him to understand as much as he can the reasons for the rejection, without hurting him with information which he could not understand fully. In short, therapeutic tact should be used so that it will not be a traumatic experience.

Beres asked Watson whether or not an institute would have any legal liability if they were to reject a candidate without giving him any explana. tion. Watson doubted that there was any present liability. He suspected these questions lay in the future. He reiterated the fact that it should not be forgotten that he is not a lawyer and therefore his observations about law should always be in the context of caveat emptor-which translates approximately in this context to, "listener beware." Katz, responding to the same question, first reiterated a point made by Watson, that most of us are frightfully ignorant about the legal implications of what we do. He went on to say that there is another issue involved here. Before turning to a matter of law, we should always first reflect on our professional responsibility about the matter under consideration. For example, why do we want to inform or not inform a potential candidate about the reasons for his rejection by an institute? In this circumstance there would be no reason for not giving him this information; it would show respect for his person to do so. There may be 
some occasions when he would not wish to tell him everything, but then we should inform him of that fact. We would then be prepared, should he de. cide to sue, to justify why we did not wish to tell certain kinds of things and, at that point in time, our reasons could be presented to the court. Under those circumstances, it is probable that the court would not only listen to our reasons but also give them weight. He concluded by saying, "The problem is that in the area of professional responsibility not only lawyers but psy. chiatrists and psychoanalysts as well have not sufficiently thought through what the ambit of their professional responsibility is."

Two questions from the audience were addressed to Dr. Lifschutz: (1) "Should we or should we not maintain records?" and (2) "How would things have been different in this case if you had kept no records and then gone on to say that you did not remember the details of the case?" Lifschutz said that one is vulnerable for whatever record one keeps. He cited a comment by the chairman of an educational committee who stated that he had no legal problem because he had no records. Therefore, if he were to receive a subpoena, he would merely say that he did not remember the case. With regard to the latter question, Lifschutz noted that in the instant case he probably would have had no problem if he had not remembered and if he had no records, but the simple fact was that he did remember and he did have records.

With reference to records, Watson thought one should first ask the question, "What are records for?" In relation to legal matters, they have two functions: (1) to refresh our memory about what we are doing for a patient in order that we may maintain our own working contact with a patient accurately. (This purpose, he observed, is not much used by the analyst in day-to-day work with the patient.) (2) In the event the therapist is called to account legally for his work with the patient, records add substantially to what lawyers call his credibility. Mere absence of records will not keep one from being subpoenaed. There are evidentiary dangers in saying that you do not remember things about a patient whom you have treated. He suggested that a good cross-examining lawyer would then tax the analyst's narcissicism rigorously as he began to explore the implications of nonmemory about the case. That could cause the therapist considerable embarrassment when he found himself in the position of saying he treats patients but does not remember anything about them. In other words, one should not fool oneself into believing that the problem of testimony will be solved by "not having any records." Neither will it be possible to readily convince the judge that he should pay attention to your notions of relevance, when you cannot demonstrate what you did through some kind of record. In short, Watson suggested, if you jeopardize your credibility with the judge by playing games about memory, it is very likely he will pay no attention to you when you attempt to argue that certain matters are irrelevant and also damaging to your patient, so far as privilege is concerned. Therefore, such a tactic would be basically foolish and self-defeating. 
Another question addressed to Dr. Watson was, "When third party payments are part of an analysis and periodic reports are required (as with somebody treated under U.S. Government aegis), the patient must agree to such minimal reporting. Can you envision that confidentiality, privilege, and privacy could still be adequately protected?" The questioner then gave an example of such a report: "Mr. $\mathrm{X}$ is continuing in his psychoanalytic treat. ment. It is my considered opinion that authorization for an additional 90 days of treatment be given."

Watson noted that in every case, the therapist should first contact the person soliciting information and ask for a precise description of the use to be made of the data sought. This can be done tactfully, with the comment that the therapist wishes to make sure he provides information useful for the purpose. After such clarification, the therapist may then clearly contract with his patient about the precise nature of the information which he shall pass on. Such a procedure optimally guards against inappropriate passage of information, even while it solves the problem raised by the third party. Katz suggested that the American Psychoanalytic Association initiate discussions with insurance companies and with government agencies in order to clarify fully what kind of information they want and need, in order to assure that they get this information with either minimal or no breach of confidentiality. This had been accomplished in Connecticut by professional organizations. It would help to protect all therapists and their patients from inappropriate requests. If the matter can not be handled this way, then perhaps in the future some therapist will have an appropriate case in which to make a legal challenge which could lead to a ruling that would clarify the issues. It would be a case in which the analyst, the analysand, and the professional organization would all join to press for adequate clarification.

The next question was addressed to Dr. Katz: "A patient has been denied entrance to military service on the basis of psychiatric examination at the induction physical. He wishes to serve. Your opinion is that no psychological reason exists why he cannot, and he requests you to send a letter to his draft board saying he is fit. What do you do? Docs this situation pose any problems regarding your assumptions?" Katz's simple answer was, "Yes, why not write a letter to the draft board?" He asked that the question be pressed further. The questioner reiterated his point that it seemed to him that this involved the patient's forcing the analyst to protect him or not protect him in some way or other. Katz repeated his earlier statement that the important thing is for the analyst to clarify whether this is a matter of acting out, a struggle for the patient to get a declaration of concern from the analyst, etc. In short, he would analyze it as best he could. In the end, regardless of what analytic meaning it might have, he would accede to his wishes and write the letter. He might then make a referral to another analyst to complete the analysis.

Lifschutz joined with Katz in commenting that always the crucial thing is to analyze the meaning of the desired communication so far as the person 
is concerned. More often than not, that will resolve the problem. In fact, situations involving an actual subpoena are extremely rare and probably most therapists have never had the matter arise. Lifschutz used Marcovitz's example of the homicide threat to illustrate the way proper analytic processes can resolve the problem.

The following point was put to Lifschutz: "Please have Dr. Lifschutz respond to what appears to be a misconception by Dr. Watson-namely that Dr. Lifschutz's patient did not request information be divulged, but rather the defendant's lawyer requested it. It seems that Dr. Lifschutz was protecting his former patient, as well as his privilege of silence." The second question to Lifschutz was, "Did Dr. Lifschutz ever discuss his attitude and behavior with his former patient?" Lifschutz answered the last question first by saying that he had not. He never saw the patient subsequent to terminating treatment 14 year carlier. Lifschutz confirmed the questioner's comment and noted that in fact the plaintiff, the former patient, did not want him to talk about the case. This was in face of California law in which there is an automatic waiver when a personal injury matter is posed. The patient's opposition was briefly raised during the taking of the deposition. However, plaintiff's counsel quickly withdrew his objection in the face of defendant's statement of the law. From that point on, it appeared that the principal opposition to revelation was Lifschutz's own. It is Lifschutz's opinion that the law was not clear on the confidentiality matter at that time.

Robert Kohrman expressed his pleasure that the issue of privilege and confidentiality had been separated and clarified. In his opinion much of the difficulty we encounter arises because we do not have a clear metapsychology about the nature of confidentiality. Confidentiality has something to do with basic dynamics involving trust. He also related confidentiality to problems of free association and to the patient's wishes to evade superego dictates. The analyst must do something to protect the patient against the punishment of the superego for such evasions. This is not a moral but an ethical issue. "Ethical issues are originally ad hoc, pragmatic questions which later then become institutionalized, and we call them mores or morals." He himself had vigorously opposed the filing of an amicus brief by the American Psychoanalytic Association, and wished to take strong exception to Katz's comments about placing Lifschutz among the medical martyrs. He felt that such was not the case.

Kohrman suggested a tactic which he utilized with his child patients, in which he will send the insurance company's form letter to the parent and tell them to take care of it. The parent then usually comes back, having explored the matter, saying that all the company wants to know is something about the duration of the treatment and its nature. This results in an adequate communication, and there is no passage of intimate information about the patient.

Kohrman then turned to his principal concern which relates to child analysis. In "modern child analysis" most analysts have little to do with the 
parents and reveal little to them about the analytic work. This has nothing to do with the issue of confidentiality, but rather has to do with principles of transference analysis. What child analysts do or don't do has very little bearing on any of the arguments about revelation or nonrevelation.

In final comment, Katz remarked that the designation of martyr is not ordinarily bestowed on contemporaries. He jokingly commented, "Who knows, perhaps we may one day refer to Dr. Lifschutz as 'St. Joseph!' "'

In his final remarks, Lifschutz alluded to his embarrassment about the potentiality of sainthood and then noted that he wished there had been more opportunity to discuss some of the legal implications regarding the matter of the analyst possessing the right of privilege. Perhaps the time is premature for analysts to possess such a right, given their relative ignorance on these matters.

Marcovitz, in his final statement, said that in his opinion any categorical rule is antithetical to the process of analysis. Any extreme position, rigidly held, would appear to him to be most contrary to the whole theory and concept of psychoanalysis.

Watson noted that in our society only the law has the prerogative of deciding "who may do what to whom and under what circumstances." These functions have been delegated by society to the law, and we must never forget this as we attempt to resolve problems in our area. We should pay attention to what happened in malpractice law, where the medical community tended to resist participation. The law merely worked out a "flanking" maneuver so that it could solve its problems without benefit of medical testimony. The end result was to disadvantage medicine, rather than to help it-something which had been originally thought to be the gain of nonparticipation.

Submitted December 22, 1971

Children's Psychiatric Hospital

University Hospital

Ann Arbor, Michigan 48104 